\title{
COMPORTAMENTO OU INSTITUIÇÕES? A evolução histórica do neo-institucionalismo da ciência política*
}

\section{Paulo Sérgio Peres}

\section{Introdução}

As decisões políticas são o resultado direto das preferências de indivíduos que agem isoladamente e de forma egoísta ou são processos induzidos por instituições políticas e sociais que regulam as escolhas coletivas? Em outras palavras: o comportamento dos atores é determinado por alguma

* Manifesto meus sinceros agradecimentos aos pareceristas anônimos da RBCS pelas observações críticas e valiosas sugestões que fizeram ao texto. $\mathrm{Na}$ medida do possível, procurei incorporar as alterações, bem como os esclarecimentos sugeridos. Agradeço também à Fundação de Amparo à Pesquisa do Estado de São Paulo - FAPESP - pelo suporte financeiro concedido à época em que realizei o estudo bibliográfico necessário à redação deste texto. Agradeço ainda a Raquel Weiss pela tradução das citações bibliográficas que estavam originalmente em inglês.

Artigo recebido em dezembro/2007

Aprovado em junbo/2008 racionalidade endógena ou, de maneira inversa, por algum tipo de restrição exógena, configurada pelo arranjo institucional que delimita o contexto da tomada de decisão? Estas têm sido questões centrais na demarcação teórica de dois tipos de abordagem que competiram e dominaram o desenvolvimento da Ciência Política desde os primeiros decênios do século XX, quais sejam, o institucionalismo e o comportamentalismo.

No âmbito desse embate, e após duas "revoluções" de paradigma, uma nova abordagem veio a prevalecer na análise do fenômeno político nos últimos quarenta anos - o neo-institucionalismo. $\mathrm{Na}$ verdade, o paradigma neo-institucional, atualmente, é hegemônico na Ciência Política. E esta não é apenas uma impressão gerada pelas recorrentes declarações de adesão aos seus postulados básicos que podem ser encontradas ou na introdução ou nas secções teóricas de livros e artigos científicos; sua hegemonia pode ser objetiva e estatisticamente 
constatada pelo exame dos temas abordados, da metodologia empregada e das premissas adotadas por diversos investigadores nos artigos publicados nos principais periódicos internacionais (cf. Riba, 1996).

Diante desse fato, é possível concluir, de acordo com a perspectiva de Kuhn (1962), que a maioria das pesquisas empreendidas pelos cientistas políticos no contexto atual é uma atividade de "ciência normal" no âmbito do paradigma neo-institucionalista; atividade esta voltada à resolução de "quebra-cabeças" empíricos e metodológicos. Com efeito, é em torno desse paradigma que se movimenta e se organiza a comunidade desse campo científico, fazendo avançar o conhecimento acerca dos fenômenos políticos no interior de seu próprio sistema cosmológico. Este, por sua vez, abrange os fundamentos ontológicos e epistemológicos da abordagem neo-institucionalista, cuja premissa básica é a idéia de que, para usar expressões consagradas, as "instituições importam" decisivamente na produção dos resultados políticos.

Conforme já discutido por alguns autores (por exemplo, Barry, 1978; March e Olsen, 1984; Almond, 1988; Dryzek e Leonard, 1988; North, 1990; Eggertsson, 1990; Dimaggio e Powell, 1991; Blackhouse, 1994; Mäki e Knudsen, 1993; Knight e Sened, 1995; Nee, 1998; Simon, 2000), há pelo menos três áreas das ciências humanas nas quais, nos últimos quarenta anos, ocorreu a retomada do viés institucional como premissa analítica - a Economia, a Sociologia e a Ciência Política -, assim como no caso da abordagem da política, ainda segundo alguns autores (Hall e Taylor, 1996; Kato, 1996; Norgaard, 1996), também haveria uma subdivisão em três tipos de enfoque - "institucionalismo histórico", "institucionalismo sociológico" e "institucionalismo da escolha racional".

Conseqüentemente, vários autores vêm discutindo as diferenças e as semelhanças entre as vertentes neo-institucionais das referidas áreas de conhecimento, bem como das escolas que co-habitam o campo da análise política. Contudo, curiosamente, há poucos trabalhos concentrados no próprio desenvolvimento histórico de tal paradigma na Ciência Política. Sob tal perspectiva, meu objetivo neste texto é fazer uma breve reconstrução histórica do desenvolvimento teórico e metodológico do paradigma neo-institucionalista da Ciência Política a partir da concepção de "revolução de paradig- mas" - enquadramento também já utilizado, em alguma medida, por alguns autores (cf. Almond, 1996; Gunnell, 2004a, 2005). Como procurarei mostrar, no caso específico da abordagem política, tal revolução envolveu dois processos sucessivos, sendo um deles de oposição e o outro de síntese. No primeiro caso, uma oposição radical à abordagem comportamentalista que floresceu nos anos de 1920-1930 e se tornou hegemônica ao longo das décadas de 1940-1950-1960; no segundo caso, a articulação sintética de elementos do próprio comportamentalismo com elementos do que se convencionou chamar de antigo institucionalismo.

\section{A revolução comportamentalista como reação ao antigo institucionalismo}

\section{$O$ antigo institucionalismo}

Em setembro de 1961, Emmette Redford, em seu discurso como presidente da American Political Science Association [APSA], destacou à sua audiência os avanços pelos quais a Ciência Política estava passando naquele momento. Segundo ele, estaria em curso uma radical mudança quanto à abordagem do fenômeno político que, até meados dos anos de 1940, era centrada em análises especulativas, descritivas e formalistas, inspiradas pela Filosofia Política e pelo Direito. Tais abordagens eram caracterizadas como institucionalistas e, posteriormente, vieram a ser chamadas de antigo institucionalismo, de forma que pudessem ser diferenciadas das abordagens neo-institucionais surgidas na década de 1970 (Somit e Tanenhaus, 1967; March e Olsen, 1984; Dryzek e Leonard, 1988; Dimaggio e Powell, 1991; Sened, 1991; Almond, 1996; Hall e Taylor, 1996; Remmer, 1997; Nee, 1998; Peters, 1998; Lane e Ersson, 2000).

Não obstante, é importante que se diga, já era bastante longa a tradição dos estudos institucionais, remontando, grosso modo, a Aristóteles com sua clássica análise das constituições atenienses, sendo revitalizada a partir do século XVII, com a sistematização do contratualismo moderno por Locke e aprimorado, em seguida, por Montesquieu, na primeira metade do século XVIII, quando a ênfase recaiu sobre a centralidade das leis e dos costumes como instituições fundamentais da dinâmica política. Ainda nas décadas finais do século XVIII, a 
perspectiva institucionalista recebeu enorme contribuição do debate dos artigos federalistas norte-americanos, pela ótica dos quais as instituições, acima de tudo, tornar-se-iam objetos de uma "engenharia constitucional", para usarmos um termo difundido por Sartori (1997).

Na primeira metade do século XIX, foi a vez de Tocqueville valorizar as instituições sociais e políticas como as variáveis explicativas da bem-sucedida democracia republicana presidencialista dos Estados Unidos. Outro exemplar significativo desse tipo de enfoque é o trabalho de Walter Bagehot, The English constitution, publicado em 1867, no qual o autor inglês comparava os modelos constitucionais britânico e norte-americano, de forma a ressaltar as supostas vantagens do primeiro sobre o segundo, especialmente em função da adoção da monarquia parlamentarista com constitucionalismo moderado, ou seja, com reduzido grau de dispersão do poder político.

Também na segunda metade do século XIX e avançando sobre as primeiras décadas do século XX -, foi a vez da Economia Política dirigir o foco de suas discussões aos possíveis efeitos das instituições e da cultura sobre o comportamento econômico dos indivíduos. A querela metodológica notoriamente conhecida como methodenstreit - que opôs, de uma parte, a escola "dedutiva" e "axiomática", representada pelo austríaco Carl Menger, e, de outra, a escola "histórica" e "institucional" alemã, representada por Gustav Schmoller, redundou na prevalência da vertente institucional no pensamento econômico norte-americano, cenário em que Thorstein Veblen, John Commons e Weslei Mitchell foram figuras de destaque na defesa da importância dos hábitos e da cultura - ou seja, das instituições sociais - como variáveis explicativas fundamentais, tanto dos processos econômicos, quanto dos processos políticos (cf. Blaug, 1993). Também no início do século XX, a própria Sociologia, ainda emergente como uma ciência empírica da moral, e bem representada por Émile Durkheim - mas, obviamente, não apenas por este -, do mesmo modo, tomou as instituições sociais - tanto em termos estáticos, como em termos históricos - como sua unidade de análise e instância observacional (cf. Barnes, 1948). Entretanto, esse institucionalismo ainda era extremamente formalista e normativo.

No caso da política, os estudiosos preocupavam-se mais em analisar criticamente "a letra" das constituições de cada nação, com a intenção de modificá-las de acordo com princípios gerais, deduzidos do próprio pensamento racional que contempla "O Bem", levando em consideração os melhores e os piores efeitos, as vantagens e as desvantagens de cada modelo constitucional para a consecução dos objetivos mais nobres da humanidade - realização mesma daquele suposto "Bem". Devido a tal postura, esses estudiosos preocupavam-se muito mais em estabelecer modelos prescritivos de "desenho constitucional", sob uma ótica normativa do que deveria ser a política, do que em se concentrar em "fatos objetivos", em dados empíricos da dinâmica real dos atores e dos comportamentos (cf. Somit e Tanenhaus, 1967; Farr, 1995; Peters, 1998; Gunnell, 2005, 2004a).

Ocorre que, àquela altura, essas abordagens, de natureza bastante formal, começavam a ser consideradas ineficientes para a explicação dos novos fenômenos políticos que surgiram a partir da década de 1930 - o nazismo, o fascismo, as crises do liberalismo e da representação, a apatia e a alienação políticas etc. Em decorrência disso, depois da Segunda Guerra Mundial, os estudos passaram a enfocar a dinâmica "real" da política, com ênfase na investigação factual, na proposição de hipóteses testáveis e na busca de generalizações empíricas (Dahl, 1963; Somit e Tanenhaus, 1967; Dryzek e Leonard, 1988; Farr, 1995; Almond, 1996). Esses novos estudos não apenas passavam a incorporar as técnicas mais avançadas de análise estatística principalmente com pesquisas de opinião e construções de escalas -, como passavam também a abranger outros países, de forma a agregar à Ciência Política o método comparativo (Chilcote, 1996), já bastante utilizado na Sociologia e na Antropologia. Redford (1961) chamou a esse processo de "eruptions in our discipline", especialmente por causa da ruptura epistemológica introduzida, que conduziu a grandes avanços na sofisticação analítica e metodológica.

Deve ser destacado também que, na perspectiva de Gunnell (1993, 2004b, 2005), tal oposição continha uma disjuntiva teórica e normativa bem mais profunda, herdeira direta do grande problema político do século XIX, que era o de se estabelecer a forma e a modalidade de incorporação das massas à política. Tal problema opunha a visão pluralista da democracia à visão republicana. Segundo ele, a visão republicana estaria vinculada ao normativismo 
da Filosofia Política e aos ideais rousseaunianos de uma democracia direta e harmônica, enquanto o pluralismo estaria vinculado à concepção psicológica e sociológica do conflito social entre grupos de interesse e da democracia representativa. Segundo Gunnell, "o ataque pluralista contra a idéia de soberania do Estado significou muito mais do que uma rejeição das análises legalistas e institucionalistas. Ele significou, com efeito, um ataque à idéia predominante de soberania popular" (2005, p. 598). ${ }^{1}$

Seja como for, mesmo que de maneira sucinta, o que o presidente da APSA estava a caracterizar em seu discurso era o que passou a ser designado como a "revolução comportamentalista" no campo da Ciência Política. Mas, afinal, o que foi essa "revolução comportamentalista"? Quais foram suas principais características e quais suas limitações analíticas? Enfim, quais as contribuições que o comportamentalismo trouxe à Ciência Política?

\section{Características gerais do comportamentalismo da ciência politica}

Logo de início, é preciso ressaltar que o comportamentalismo é, antes de tudo, uma designação genérica do behaviorismo, cuja extensão é bastante ampla e cuja formulação inicial adveio da psicologia norte-americana. O texto considerado o ponto inicial do behaviorismo foi publicado por Watson ([1913] 1997) em uma revista de Psicologia, sob o título bastante curioso de "A psicologia como um comportamentalista a vê". Nele, o autor abre a discussão com uma declaração que não deixa margem para dúvidas: "a Psicologia, tal como concebida pelo comportamentalista, é um ramo estritamente objetivo e experimental da ciência natural. A sua proposta teórica consiste em prever e controlar o comportamento" (Idem, p. 158).

Portanto, as proposições básicas formuladas por John Watson surgiram como oposição às perspectivas teóricas e analíticas da Psicologia da época, marcadas pelo método introspectivo e pela análise dos processos mentais da consciência (cf. Adcock, 1959; Henneman, 1966; O’Donnell, 1987; Wozniak, 1995; Baum, 2005). Contrariamente, a ênfase de Watson foi dada à busca de maior cientificidade objetividade - na análise psicológica, o que o levou a propor o abandono de especulações subjetivas em favor de métodos de observação aplicados a objetos realmente passíveis de serem investigados em laboratório. Esse "objetivismo" implicaria no deslocamento da perspectiva investigativa, passando dos fenômenos mentais para a observação empírica do comportamento (cf. Watson, [1913] 1997). ${ }^{2}$

Desse modo, a Psicologia aderiu de forma vigorosa ao comportamentalismo, que, pouco depois, espalhou-se pelas Ciências Sociais. Em realidade, na Sociologia já havia sido dado anteriormente um passo importante na direção de uma abertura às influências do comportamentalismo. Entusiasmado e, de certa forma, inspirado pelos experimentos de Wilhelm Wundt e pelo seu laboratório de Psicologia, na Alemanha, Émile Durkheim (1897) procurou demonstrar, na prática, por meio de sua obra pioneira e fundadora de análises multivariadas - O suicídio - , a importância da observação dos comportamentos como a expressão objetiva e "mensurável" da moral, entendida como fonte de coesão/solidariedade social. ${ }^{3}$ Anos depois, Bronislaw Malinowski (1922, 1944), na Antropologia, ressaltou a necessidade de investigações diretas, sem mediações, com aprofundados levantamentos de dados de campo por intermédio de densas descrições de comportamentos. ${ }^{4} \mathrm{O}$ método etnográfico da "observação participante", de algum modo, representou a busca de maior cientificidade na Antropologia e, de certa forma, uma aproximação em relação a algumas premissas metodológicas do comportamentalismo (cf. Malinowski, 1970). ${ }^{5}$

Assim como em pelo menos parte da Antropologia e da Sociologia daquele período, na Ciência Política, o behaviorismo também representou uma rejeição às análises e aos métodos empregados até aquele momento. Em realidade, é possível afirmar que a adoção do paradigma comportamentalista na análise dos fenômenos políticos ocorreu como um movimento acadêmico de rejeição ao antigo institucionalismo. Dahl salienta isto, observando que:

Considerada historicamente, a abordagem behaviorista era um movimento de protesto que teve lugar no interior da Ciência Política. [...] Termos tais como comportamento político e abordagem comportamentalista passaram a ser associados a certo número de cientistas políticos, especialmente americanos, que compartilhavam uma insatisfação em relação às realizações da Ciência Política convencional, especialmente no caso das abordagens históricas, filosóficas e da descrição institucional (1961, p. 766).

Ocorre que a Ciência Política tradicional era predominantemente institucionalista; e foi contra 
esse [antigo] institucionalismo que o comportamentalismo se insurgiu. Afinal, segundo enfatizam Steinmo et al., "era óbvio que leis formais, regras e estruturas administrativas não explicavam realmente o comportamento político ou os resultados políticos" (1997, p. 3). Porém, além do protesto contra $\mathrm{o}$ institucionalismo formalista na defesa de maior cientificidade, vários outros fatores de ordem prática contribuíram para a emergência e o reconhecimento acadêmico da escola comportamentalista (cf. Somit e Tanenhaus, 1967; Farr, 1995; Almond, 1996; Miller, 1998). Neste caso, é possível destacar pelo menos quatro dos mais importantes.

O primeiro desses fatores foi a desvalorização, pelo governo norte-americano, dos trabalhos de cientistas políticos institucionalistas, especialmente pela clara incongruência entre as digressões teóricas produzidas e os imperativos impostos pela prática do governo no período da Guerra Fria. Em segundo lugar, a incapacidade que os teóricos institucionalistas mostraram diante da necessidade de explicação sistemática de fenômenos importantes da época, como o nazismo, o fascismo e o socialismo, o que acarretou na perda de terreno acadêmico-institucional para outras ciências, como a Sociologia, a Psicologia e a Economia. Em terceiro, a ineficácia da aplicação, logo depois da Segunda Guerra Mundial, do modelo político norte-americano - democracia com capitalismo - em países não-industrializados, o que impôs a necessidade de estudos empíricos comparativos (cf. Chilcote, 1996) - neste caso, inclusive, favorecendo a emergência e a proliferação dos estudos comparativos da escola comportamentalista, com a ênfase analítica recaindo sobre a cultura política e as atitudes psicológicas dos atores sociais (cf. Almond e Powell, 1966; Eckstein, 1988; Pasquino, 1994; Chilcote, 1996). Finalmente, o fator de maior relevância foi a grande influência que pesquisadores e teóricos europeus exilados, e que se instalaram nas universidades norte-americanas, exerceu na formação de novos cientistas políticos e na condução de pesquisas sociais (Somit e Tanenhaus, 1967; Almond, 1996). Esses intelectuais trouxeram maior rigor teórico, novas perspectivas analíticas, habilidades em estatística e, acima de tudo, uma visão multidisciplinar, contribuindo enormemente para que a Ciência Política se tornasse uma ciência bastante eclética e pluralista do ponto de vista metodológico.

Dahl enfatiza este último aspecto, afirmando que "boa parte desses especialistas que ocupavam posições de liderança em departamentos de Sociologia e de Ciência Política insistiam na relevância das teorias sociológicas e psicológicas para o entendimento da política" (1961, p. 766). Pasquino segue o mesmo mote e ressalta que:

Pelo próprio fato de tomarem de empréstimo o nome de uma escola psicológica e por seu interesse pelo homem concreto, os comportamentalistas foram sempre profundamente atraídos pela Psicologia. Paralelamente, a Antropologia, a Sociologia e, por seu rigor e relativa perfeição técnica, a Economia, foram as disciplinas às quais os comportamentalistas mais recorreram (1994, p. 187).

Entretanto, é importante assinalar uma pequena incorreção de Pasquino (1994) e que ainda persiste em vários autores. Nesse primeiro momento - entre as décadas de 1940 e 1960 -, as maiores influências metodológicas absorvidas pela Ciência Política comportamentalista vinham da Sociologia, da Antropologia e da Psicologia, e não tanto da Economia. Nesse mesmo período, havia predominado na Economia a perspectiva neoclássica da "escola inglesa" em relação à "escola histórica" alemã e à "escola institucionalista" vebleniana norte-americana. Rivalizavam com a "escola inglesa", a "escola austríaca" e a "escola monetarista" de Chicago, representada por Friedman. O ponto central da controvérsia residia na adoção de uma metodologia formalista, portanto, dedutiva e abstrata, ou de uma metodologia realista, portanto, indutiva e histórica. Friedman, com seu empirismo pragmático - assim como os adeptos da "escola austríaca" -, advogava uma teoria de pressupostos irrealistas. Assim, começava a se firmar na economia a metodologia dedutiva com modelos teóricos formais, centrados nos fundamentos neoclássicos acerca das motivações e do comportamento dos indivíduos. ${ }^{6}$

Àquela altura, a Ciência Política ainda adotava premissas indutivas de abordagens culturalistas e históricas. A absorção do formalismo da perspectiva econômica somente veio a acontecer a partir dos anos de 1960, com a crescente adoção do individualismo metodológico. $\mathrm{Na}$ prática, isso significou um afastamento em relação às premissas sociológicas e antropológicas.

De qualquer modo, conforme observa Redford, a perspectiva interdisciplinar somente foi viável devido ao entrecruzamento de interesses das várias disciplinas que se autodenominavam "ciências do comportamento". Por isso, o cientista político 
comportamentalista pôde integrar diversos enfoques e diversas metodologias, uma vez que, segundo o autor, "ele encontrou um ponto de interesse em comum com os psicólogos, sociólogos e antropólogos culturalistas - grupos que também estavam interessados no comportamento humano" (1961, p. 757). Dahl concorda com este argumento e ainda ressalta que a perspectiva multidisciplinar foi um dos méritos da escola comportamentalista, afinal, "uma conseqüência desse protesto behaviorista foi a restauração da unidade entre as ciências sociais, ao promover uma aproximação dos estudos políticos com esses métodos, teorias, pesquisas e resultados da moderna Psicologia, da Sociologia, da Antropologia e da Economia (1961, p. 770).

Já com relação à ênfase dada à orientação empírica e positiva - axiologicamente neutra -, Leiserson chama a atenção para o fato de que:

Do ponto de vista behaviorista, é muito mais importante que a pesquisa política seja voltada para os dados sobre a influência dos seres humanos sobre os processos governamentais, sobre o modo como constituem esses processos e são influenciados por eles e, particularmente, que a pesquisa não se apóie em argumentos sobre as prioridades das diferentes Ciências Sociais. Em suma, a pesquisa de comportamento político busca, em primeiro lugar, dados que expressem o comportamento humano em tipos de situações que envolvem o exercício da autoridade governamental, em vez de encontrar evidências que glorifiquem ou condenem entidades personificadas, tais como o Estado, a sociedade, a comunidade, a economia ou a classe, dotadas de qualidades tais como onisciência, onipotência e inevitabilidade (1956, pp. 55-56).

Em suma, portanto, a "revolução comportamentalista" da Ciência Política é caracterizada por dois pontos fundamentais. O primeiro deles é sua posição duramente crítica em relação à abordagem institucionalista de então, propondo, em oposição, uma teoria positiva e uma análise empiricamente orientada e bem mais rigorosa em termos conceituais. O segundo ponto é sua proposta programática de utilizar, de maneira pluralista, abordagens metodológicas de outras ciências "vizinhas", como a Sociologia, a Antropologia e a Psicologia. Estes dois pontos compuseram as forças motrizes fundamentais de sua busca de maior cientificidade e de maior reconhecimento social.

$\mathrm{Na}$ verdade, a utilização de teorias empiricamente orientadas e de técnicas mais apuradas para pesquisas de observação correspondia aos anseios de alguns pioneiros na reivindicação de uma Ciência Política mais científica, ainda em seu início nos Estados Unidos, no começo do século XX (cf. Somit e Tanenhaus, 1967; Gunnell, 2004a, 2004b, 1993, 1988). Muitas de suas características podem ser identificadas nas propostas que um dos fundadores da Ciência Política norte-americana, tal qual a conhecemos atualmente, já defendia na década de 1920. Trata-se de Charles Merriam (1874-1954), considerado um dos principais cientistas políticos da terceira geração desses intelectuais naquele país, ${ }^{7}$ assim como também é considerado o iniciador da abordagem comportamentalista na política (Somit e Tanenhaus, 1967; Jensen, 1969). ${ }^{8}$ Ele foi professor do Departamento de Ciência Política da Universidade de Chicago ${ }^{9}$ e sua aproximação do comportamentalismo ocorreu no contexto da influência que a Psicologia exercia no ambiente daquela universidade naquele período. ${ }^{10}$

Merriam antecipava que "algum dia poderemos adotar outro ângulo, diferente do ângulo formal, assim como o fazem outras ciência, e, assim, começar a olhar para o comportamento político como um dos principais objetos de investigação" (1925, p. 7). De fato, como pretendia o autor, com a emergência da escola comportamentalista, houve um deslocamento radical do foco de investigação, que até então era mais voltado às instituições jurídicas e administrativas, para os atores políticos; mais especificamente, seu comportamento, seus valores, seus objetivos. ${ }^{11}$

$\mathrm{Na}$ visão de Redford, essa mudança de enfoque teria provocado, inclusive, uma completa alteração na formação e na postura epistemológica dos cientistas políticos, na medida em que "o behaviorismo volta sua atenção para a ação política das pessoas em vez de voltar-se para instituições, acontecimentos ou ideologias [...]" (1961, p. 756). De fato, tal ruptura epistemológica causou tanto impacto que alguns cientistas políticos a caracterizaram como uma "revolução científica" nos moldes kuhnianos. Este é o teor de pelo menos três discursos presidenciais da APSA, ${ }^{12}$ nos anos de 1960, totalmente dedicados à questão (Truman, 1965; Almond, 1966; Easton, 1969).

\section{Inovações teóricas e metodológicas do paradigma comportamentalista}

De forma geral, a "revolução comportamentalista” trouxe várias contribuições à Ciência Políti- 
ca. Entre elas, uma grande preocupação com objetividade e com generalizações indutivas, elementos considerados essenciais à análise científica. Com efeito, estes são os pontos diretamente relacionados com a proposta comportamentalista: (a) descrições objetivas, (b) generalizações empíricas, (c) métodos sistemáticos e diferenciais, (d) material empírico, (e) quantificação e (f) multidisciplinaridade teórica e metodológica. Mas, acima de tudo, a maior contribuição, segundo Somit e Tanenhaus, foi a seguinte:

O behaviorismo tornou os cientistas políticos mais autoconscientes e mais autocríticos, mais atentos à teoria analítica, ao desenho da pesquisa e às técnicas quanti- tativas. [Isso significa] [...] que ao menos alguns fenômenos políticos importantes poderiam ser explicados mediante leis empíricas verificadas, enquadradas em um conjunto de axiomas correlatos (1967, p. 229).

Essa postura metodologicamente rigorosa pode ser sintetizada em oito pontos fundamentais da agenda de pesquisa comportamentalista, conforme listados no Quadro 1 (cf. Morgenthau, 1946; Lasswell e Kaplan, 1950; Truman, 1951, 1965; Voegelin, 1952; Easton, 1953, 1965, 1969, 1998; Eulau, Eldersveld e Janowitz, 1956; Butler, 1958; Hyneman, 1959; Dahl, 1961, 1963; Ranney, 1962; Charlesworth, 1962; Eulau, 1963; Lasswell, 1963; Young, 1958; Farr, 1995; Miller, 1998).

\section{Quadro1 \\ Síntese das Diretrizes Metodológicas do Comportamentalismo}

$1^{\circ}$ : Somente uma Ciência Política com orientação empírica e positiva é capaz de explicar cientificamente os fenômenos políticos.

$2^{\circ} \mathrm{O}$ cientista político deve se ocupar apenas de fenômenos observáveis, evitando qualquer especulação dedutiva.

$3^{\circ}$ Os dados analisados devem ser quantitativos ou, então, quantificados.

$4^{\circ}$ A pesquisa deve ser orientada e dirigida por uma teoria conceitualmente rigorosa.

$5^{\circ} \mathrm{A}$ análise deve ser pautada pela neutralidade axiológica.

$6^{\circ}$ As pesquisas devem ter caráter analítico [padrões e correlações estatísticas] e não meramente descritivo.

$7^{\circ}$ É recomendável utilizar abordagens multidisciplinares, uma vez que a Ciência Política com tal orientação seria apenas uma das ciências do comportamento.

$8^{\circ}$ Adoção do máximo de rigor metodológico, seguindo a lógica do sistema de inferência indutivo.

Assim, com tais propostas, o comportamentalismo atingiria seu ponto máximo durante os anos de 1950, persistindo de maneira hegemônica até meados da década seguinte, tanto no que se refere à adesão teórica, como no que se refere à sua preponderância nos espaços institucionais - como departamentos universitários, instituições de pesquisa e assessoria ao governo (Somit e Tanenhaus, 1967; Chilcote, 1996). Contudo, sua consolidação como principal paradigma do período não se deu de forma incontroversa; pelo contrário, foi grande a polêmica e o debate dos herdeiros do antigo institucionalismo com a nova "Ciência da Política". De fato, o comportamentalismo tanto atraiu devotos militantes como críticos ferrenhos.

\section{A revolução neo-institucionalista como reação ao comportamentalismo}

No final dos anos de 1960, em outro discurso presidencial da APSA, temos o registro da crise que tão precocemente se abatia sobre a abordagem comportamentalista. $O$ presidente daquele momento era David Easton, um dos formuladores da teoria dos sistemas aplicada à política. Em seu pronunciamento, Easton asseverava que:

Uma nova revolução estava acontecendo na Ciência Política americana. Essa última revolução - o behaviorismo - ainda não havia atingido sua plenitude, quando foi repentinamente abalada pelas crises políticas e 
sociais de nossa época. [...] Esse novo desafio voltouse contra o desenvolvimento da ortodoxia behaviorista. Chamo esse desafio de revolução pós-behaviorista (1969, p. 1051).

Ainda sem um nome preciso para o novo paradigma que começava a se sobrepor ao comportamentalismo, Easton (1969) antevia sua futura hegemonia. Esse "pós-comportamentalismo" viria a ser o que atualmente chamamos de neo-institucionalismo. Em grande parte, o neo-institucionalismo surgiu como um movimento de dupla rejeição: (1) à ausência de cientificidade do antigo institucionalismo e (2) à ausência do contexto institucional nas abordagens comportamentalistas - tanto as indutivas [sociológica, antropológica e psicológica], como as dedutivas [econômica de viés neoclássico/rational choice ortodoxa]. Dimaggio e Powell destacam tal aspecto, afirmando que o neo-institucionalismo apareceu como:

[...] uma reação contra a revolução behaviorista [...]. [...] O esforço atual para coadunar os focos de pesquisa dessas tradições com os desenvolvimentos contemporâneos nos métodos e nas teorias não significa um mero retorno às raízes clássicas, mas um esforço para encontrar novas respostas para antigas questões sobre como as escolhas sociais são moldadas, mediadas e canalizadas por arranjos institucionais (1991, p. 2).

Sob tal perspectiva, primeiramente, vejamos em linhas gerais os motivos que levaram à crise do paradigma behaviorista e como, a partir desta, criou-se um habitat favorável ao ressurgimento da abordagem institucional, uma "espécie" já quase em extinção àquela época. Depois, vejamos como essa "espécie" evoluiu para uma nova modalidade teórica e metodológica, demandando uma ampliação na "taxonomia" usual, com a introdução do termo neo-institucionalismo no "reino" dos paradigmas da Ciência Política.

\section{A crise do paradigma comportamentalista e a retomada das instituições}

De maneira genérica, as críticas ao comportamentalismo concentravam-se nas suas insuficiências analíticas - suas "dificuldades empíricas" quanto à explicação de várias dimensões do fenômeno político, de um lado, e, de outro, no seu ecletismo teórico, com sua pretensão multidisciplinar.
Com relação a este último ponto, as críticas concentraram-se no fato de que o comportamentalismo da Ciência Política acabou sendo absorvido pelo conjunto das ciências do comportamento, quebrando suas fronteiras disciplinares - o que criaria um grave problema em termos de demarcação científica. ${ }^{13}$ Dessa maneira, de acordo com Dahl (1961), o ecletismo comportamentalista acabou impondo à Ciência Política as perdas de foco e de especificidade analítica.

Mas, no que se refere aos aspectos teóricos do behaviorismo, a crítica apresentada por Dahl (1961, p. 770) foi ainda mais profunda, na medida em que explicitou suas reticências quanto à insuficiência de uma explicação voltada exclusivamente à ação dos indivíduos, em que se faz tábula rasa do contexto institucional da esfera estritamente política. Do mesmo modo, o autor já chamava a atenção para os paradoxos inerentes à ação coletiva, demonstrados há pouco por Arrow (1951), e que viriam a ser mais bem desenvolvidos posteriormente pela teoria da escolha social:

\footnotetext{
As mais importantes produções da abordagem comportamentalista até o momento lidaram com indivíduos - indivíduos que votam, que participam da política de várias maneiras, ou que expressam certas atitudes ou crenças. Mas, um indivíduo não é um sistema político, e a análise das preferências individuais não pode explicar plenamente as decisões coletivas, as quais somente poderão ser explicadas se entendermos os mecanismos pelos quais as decisões individuais são agregadas e combinadas nas decisões coletivas (Dahl, 1961, p. $770)$.
}

Portanto, além dos problemas demarcatórios, de um lado, e da perda da especificidade analítica, de outro, o programa de pesquisa comportamentalista entrou em crise especialmente por não ter se revelado bem-sucedido teórica e empiricamente à medida que suas proposições foram sendo submetidas a testes e a refutações, tanto factuais como lógicas. Assim sendo, é possível afirmar que a rejeição ao paradigma comportamentalista se sustentou em pelo menos oito críticas centrais, tal como sintetizadas no Quadro2 (cf. Dahl, 1961; Somit e Tanenhaus, 1967; March e Olsen, 1984; Skocpol, 1985; Dryzek e Leonard, 1988; Easton, 1969, 1998; Sened, 1991; Farr, 1995; Steinmo, Thelen e Longstreth, 1997; Immergut, 1998; Miller, 1998, Riker, 1998; Simon, 2000). 


\section{Quadro 2 \\ As Principais Críticas ao Comportamentalismo}

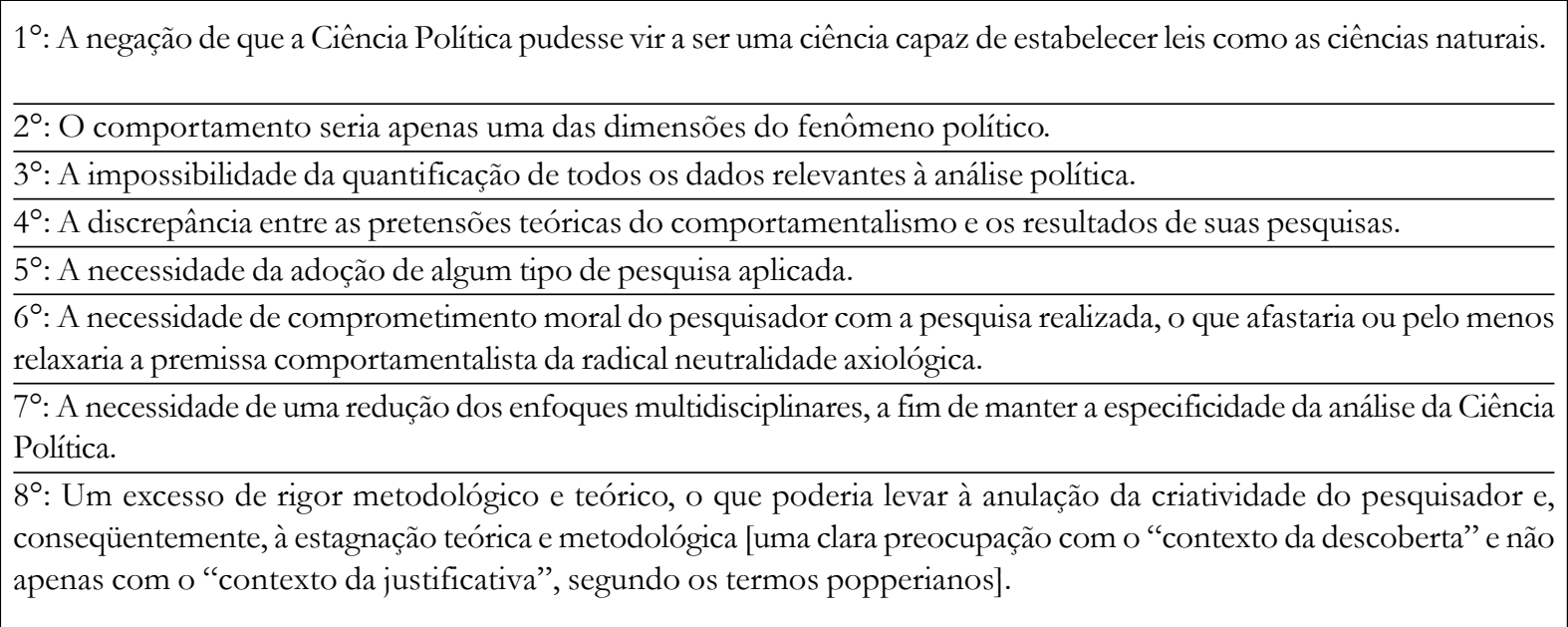

Conseqüentemente, vários analistas passaram a questionar a validade das premissas comportamentalistas, tanto da versão indutivista da Sociologia e da Antropologia, como da versão dedutivista da Economia (cf. Riker, 1958, 1998). A área em que o impacto desse movimento crítico se fez maior foi no campo de pesquisas sobre o congresso norte-americano, na medida em que os estudos dos processos legislativos daquele país passaram a ser o campo inicial da contestação empírica da validade do paradigma comportamental e da proposição de novas perspectivas teóricas para o estudo das decisões e dos resultados políticos (cf. Shepsle, 1986; Limongi, 1994). Instalou-se, assim, um período de disputas entre explicações comportamentalistas indutivas e explicações comportamentalistas dedutivas, paralelamente a explicações que buscavam evidenciar que as regras que presidiam os processos decisórios, tanto do comportamento eleitoral - sistema eleitoral -, como do comportamento parlamentar - regras do processo legislativo -, seriam as responsáveis pelos resultados políticos (cf. Riker, 1959, 1961, 1963, 1965).

Assim é que, sob pesadas críticas, o comportamentalismo perdeu força e, no final dos anos de 1960 e início da década seguinte, o paradigma institucionalista foi, então, revitalizado. A abordagem institucional ressurgiu mantendo a proposta de trazer as instituições para o centro da análise (Ostrom, 1986, 1991), mas, dessa vez, aderindo às mesmas preocupações que caracterizaram o comportamentalismo com relação à cientificidade (cf. March e Olsen, 1984; Almond, 1988; Dimaggio e Powell, 1991; Jepperson, 1991; Knight e Sened, 1995; Hall e Taylor, 1996; Kato, 1996; Norgaard, 1996; Immergut, 1998; Nee, 1998; Miller, 1998). Desse modo, o neo-institucionalismo não é apenas uma rejeição cabal do comportamentalismo, mas sim uma síntese entre este e o antigo institucionalismo. Deste último, foi mantida a centralidade das instituições na explicação do fenômeno político; do primeiro, foi mantida a preocupação com o rigor teórico - especialmente a orientação dedutiva, intrínseca ao individualismo metodológico da teoria da escolha racional (Ostrom, 1991) -, com a precisão conceitual - matemática/geométrica - e com a orientação empírica da pesquisa - aplicação de testes quantitativos.

\section{O ponto de partida neo-institucionalista}

A retomada das instituições como variáveis explicativas da dinâmica política dos atores em bases empíricas e positivas se deve a dois processos. De uma parte, a uma controvérsia teórica no campo da Economia, voltada ao problema da tomada de decisões em um contexto de escolhas coletivas. De outra parte, às conseqüências teóricas e metodológicas que tal controvérsia produziu nos estudos do congresso norte-americano a partir dos anos de 
1950-1960, aprofundando-se a partir dos anos de 1970 (cf. Shepsle, 1986; Sened, 1991; Limongi, 1994; Remmer, 1997; Riker, 1998, 1982, 1980; Nee, 1998; Peters, 1998).

Quanto ao primeiro processo, a partir dos anos de 1960, alguns analistas políticos começaram a se interessar cada vez mais pelo comportamentalismo da Economia, cujo sistema de inferências era dedutivo, assentado em premissas básicas acerca das motivações e das preferências dos indivíduos e de seu mecanismo racional - calculista e egoísta - de tomada de decisão diante de alternativas excludentes. Em relação a isso, é importante destacar que alguns economistas - tais como Schumpeter (1942), Arrow (1951), Downs (1957) e Buchanan e Tullock (1962) - contribuíram enormemente para tal atração, na medida em que, desde os anos de 1940, já vinham utilizando modelos econômicos de pensamento na análise do comportamento político, e, desse modo, acabaram sendo o ponto de partida para a "revolução" neo-institucional na política. Especialmente nos casos de Arrow (1951) e de Downs (1957), que contribuíram significativamente para a introdução mais sistemática do individualismo metodológico da matriz econômica neoclássica, em que o modelo da escolha racional tem como fundamento axiomático o comportamento "maximizador de utilidades".

Isso significa que a Ciência Política nesse momento passou a ser atraída por um modelo explicativo dedutivo, mas que ainda desconsiderava as instituições sociais e políticas como variáveis relevantes. Desse modo, economistas versados na matemática aplicada, ocupados com a formalização de fenômenos sociais, retomaram o até então esquecido "paradoxo de Condorcet" acerca dos métodos de decisões coletivas justas em assembléias, relativos à agregação dos votos e/ou preferências. Este também é conhecido como "paradoxo do voto" e foi apresentado por Nicolas de Caritat, Marquês de Condorcet (1743-1794), um matemático e filósofo francês do século XVIII, considerado pioneiro na aplicação da matemática a um fenômeno político. Num trabalho publicado em 1785, ele demonstrou matematicamente a cíclica "transitividade das preferências" num contexto de decisões coletivas, como as Assembléias.

A conseqüência mais direta de sua demonstração é que, em uma decisão coletiva por regra majoritária, não é possível encontrar uma única e invariável maioria num processo de escolha entre alternativas possíveis. Isso porque, fundamentalmente, numa decisão qualquer em relação às alternativas $A, B$ e $C$, por exemplo, a maioria pode, em sucessivas votações, preferir A a B, depois, $\mathrm{B}$ a $\mathrm{C}$, e, depois, $\mathrm{C}$ a $\mathrm{A}$, quebrando, assim, o requisito lógico da coerência - em que se $\mathrm{A}>\mathrm{B}$ e $\mathrm{B}>\mathrm{C}$, logo $\mathrm{A}>\mathrm{C}-$ e evidenciando que não há uma única maioria relativa a dado tema, mas sim diversas maiorias cíclicas e logicamente incoerentes. ${ }^{14}$

Arrow (1951) retomou esse paradoxo, levando-o a um considerável grau de profundidade analítica (Riker, 1980, 1982), de forma que seu "teorema da possibilidade" não apenas trouxe implicações para a teoria democrática, como também trouxe a necessidade de se procurar outra variável explicativa do processo político que não fosse o mero comportamento dos atores. ${ }^{15}$ Isso porque o autor demonstrou, logicamente, que em um contexto de decisão coletiva, mesmo no caso de todos os indivíduos serem racionais em termos de cálculo estratégico, as escolhas, seguindo a regra da maioria, ou seriam coletivamente irracionais - porque transitivamente incoerentes e instáveis $[\mathrm{A}>\mathrm{B}$ $>C, C>A]-$ ou, então, seriam injustas - porque contemplaria apenas uma maioria possível entre outras maiorias possíveis. Tal constatação, inclusive, abriu espaço para a suspeita de que os ideais democráticos talvez fossem irrealizáveis - decisões racionais igual e simultaneamente justas (cf. Riker, 1980, 1982).

Portanto, tal "revolução" germinou a partir da tentativa de resolução de um problema teórico, e até mesmo normativo, relativo à possibilidade da transposição do comportamentalismo da Economia às análises políticas (cf. Riker, 1982; Searing, 1991; Sened, 1991). Esse problema consistia na dificultosa adaptação de um modelo de tomada de decisão no plano individual/micro - rational choice de matriz econômica - para a tomada de decisão no plano coletivo/macro - cujo desenvolvimento resultou na formulação da social choice theory.

Ocorre que, no modelo neoclássico da Economia, decisões egoístas no plano individual teriam uma componente altruísta "colateral", na medida em que gerariam, residualmente, digamos assim, o equilíbrio coletivo das alocações de recursos. Mas, a simulação matemática realizada por Arrow (1951), na qual era admitida a racionalidade plena dos indivíduos, demonstrava, em termos lógicos, 
que a racionalidade individual não produziria racionalidade no plano coletivo. Pelo contrário, escolhas racionais tomadas individualmente, sob determinadas condições de racionalidade, produziriam instabilidade coletiva, ou seja, conduziriam à irracionalidade do ponto de vista social. Este era um problema claramente político ao qual o comportamentalismo econômico baseado na simples e ortodoxa idéia da "escolha racional" individual não podia responder, nem do ponto de vista teórico uma vez que esse modelo não contemplaria a irracionalidade -, nem do ponto de vista empírico uma vez que, no mundo real, as decisões coletivas são tomadas com certo grau de estabilidade, ao contrário do que se poderia deduzir do modelo teórico.

Quanto ao segundo processo, a discrepância entre a demonstração matemática de Arrow (1951), pela qual as decisões coletivas seriam cíclicas e irracionais, portanto, as assembléias nunca conseguiriam decidir nada realmente - uma vez que as decisões seriam sempre instáveis -, e os dados empíricos das pesquisas sobre o Congresso norte-americano, que mostravam que os parlamentares, votando em assembléia por regra majoritária, tomavam decisões sem enfrentar o problema dos ciclos irracionais, previstos pelo autor, logo levaram os teóricos a um óbvio questionamento. Estaria incorreto o teorema de Arrow ou será que existiria alguma variável interveniente, não considerada em suas equações, que estaria a contribuir para a "anulação" do efeito esperado?

De acordo com os teóricos, o teorema estaria correto e o problema seria precisamente a não consideração de uma variável fundamental que garantiria a estabilidade das decisões: as instituições políticas. ${ }^{16}$ Ou seja, as regras que estruturam o processo decisório seriam as responsáveis não apenas pela estabilidade das decisões como também pelo próprio resultado da escolha, dado que se as decisões são estáveis, com uma maioria vitoriosa, num contexto em que várias maiorias seriam possíveis, a decisão tomada deveria conter certo grau de injustiça, pois contemplaria apenas uma maioria possível (Riker, 1980; Smith, 1988; Shepsle, 1995). Desse modo, então, cada vez mais as instituições estritamente políticas passaram a ser consideradas como as variáveis explicativas centrais dos processos e das decisões, inclusive como variáveis que condicionariam aquela que até então estava no cen- tro das análises, qual seja, o comportamento dos atores (Ostrom, 1991; Immergut, 1998).

\section{A sintese neo-institucionalista}

Como visto até aqui, é possível afirmar então que a retomada das instituições como objeto central de investigação política ocorreu, em grande parte, em função da contraposição de vários cientistas sociais em relação às propostas e às premissas comportamentalistas. Isso foi devido, fundamentalmente, à concepção de que aquelas, de alguma maneira, moldam ou condicionam o comportamento dos indivíduos, seja por meio de constrangimentos, seja por meio de restrições. ${ }^{17}$ Steinmo resume este argumento:

\begin{abstract}
As atenções voltaram-se mais explicitamente para as variáveis institucionais no final da década de 1970, em decorrência do aumento das críticas à ênfase behaviorista que predominava no campo dos estudos de política americana e de política comparada durante as décadas de 1950 e 1960, a qual - embora tenha dado atenção a aspectos da vida política que antes eram negligenciados - geralmente acabava por obscurecer a importância das estruturas socioeconômicas e políticas que moldam o comportamento de forma distinta em diferentes contextos nacionais $(1997$, p. 1).
\end{abstract}

Quanto a estes aspectos, Pierson, por exemplo, ressalta que "o surgimento do novo institucionalismo na Ciência Política reflete um renovado interesse pelo próprio modo como arranjos relativamente estáveis e rotineiros estruturam o comportamento político" (1996, p. 152). Justamente por isso, como observa Norgaard, "os institucionalistas rejeitam a proposição de que um conjunto de características comportamentais e sociopsicológicas seja suficiente para explicar a ação individual e a ação coletiva. [De acordo com eles], a ação é forjada e circunscrita pelas instituições" (1996, p. 33). Com efeito, a estruturação do comportamento pelas instituições se daria pelos mais diversos mecanismos, tanto formais como informais. Sobre este ponto, Pierson afirma ainda que:

As instituições estabelecem as regras do jogo das lutas políticas - influenciando na formação de identidades de grupo, de preferências políticas e de escolhas de coalização, bem como promovendo o aumento de poder de alguns grupos, em detrimento de outros. As instituições também afetam a atuação do governo - na medida em que interferem nos recursos administrativos e financeiros que viabilizam as intervenções políticas (Idem, p. 152). 
Portanto, a posição generalizada de rejeição às premissas comportamentalistas enfatiza que as variações quanto ao desenho constitucional - por exemplo, forma de governo, sistema eleitoral, modelo federativo, regras do processo legislativo etc. - e quanto às modalidades de interação econômica - relação entre Estado e mercado, relações contratuais de trabalho, relações entre eleitores e partidos etc. - produzem interações específicas e, dessa forma, induzem a resultados políticos diversos. Então, como sugerem Steinmo et al::

[...] De modo geral, os institucionalistas estão interessados em todo tipo de instituições sociais e estatais que moldam a maneira pela qual os atores políticos definem seus interesses e estruturam as relações de poder com os outros grupos. Portanto, essa definição também abrange outras dimensões institucionais, tais como as regras da competição eleitoral, a estrutura do sistema partidário, as relações entre os diversos setores do governo e a estrutura e a organização de atores econômicos, tais como sindicatos $(1997$, p. 2).

Mas, apesar da oposição ao comportamentalismo, especialmente por causa de sua desconsideração quanto às instituições políticas e econômicas, o ressurgimento do programa de pesquisa institucionalista herdou, por assim dizer, a preocupação com o rigor metodológico e a orientação empírica daquele paradigma. Assim, enquanto, de uma parte, os neo-institucionalistas retomaram as instituições como objeto primordial da análise, de outra parte, procuram explorar abordagens que privilegiam maior precisão conceitual e, na maioria dos casos, definições operacionais que facilitem o máximo possível o tratamento empírico de dados.

Dessa forma, uma das marcas diferenciadoras dos neo-institucionalistas em relação aos praticantes do antigo institucionalismo é a oposição que os primeiros fazem ao caráter pouco científico dos segundos, assim como a abordagem institucionalmente descontextualizada dos comportamentalistas. Paralelamente, os neo-institucionalistas mantêm o foco nas instituições, tal qual proposto pelo antigo institucionalismo, do mesmo modo que a preocupação com a acuidade científica, sugerida pelos comportamentalistas. De forma geral, esses aspectos são comuns a todos os neo-institucionalistas, na medida em que julgam que as instituições são fatores de constrangimento/restrição às e de moldagem/estruturação das ações, pois limitariam seus cursos de ação possíveis e estabeleceriam uma es- cala de racionalidade entre estes. Com isso, ao longo do tempo, as instituições moldariam/estruturariam cada vez mais as preferências.

Contudo, há uma diferenciação que deve ser feita. Na vertente sociológica, a concepção prevalecente é a de que as instituições moldariam as preferências dos atores, ou seja, o que está em questão em termos tanto teóricos como empíricos é o processo de formação das preferências. Em última instância, isso significa que o foco privilegiado da análise é o processo de socialização; no caso, de socialização política. Na vertente da Ciência Políti$\mathrm{ca}$ - em sua quase totalidade adepta ao "institucionalismo da escolha racional" -, o que prevalece é concepção de que as instituições interagem com as preferências já dadas, provocando um processo de "transição" destas em relação aos objetos, de acordo com uma "escala de utilidades". Ou seja, as instituições, como formas de restrição das decisões em favor daquilo que ocuparia o primeiro lugar numa dada escala de preferências, provocaria o deslocamento dessa escolha para objetos outros que ocupariam ou o segundo, ou o terceiro, ou o quarto lugar de suas preferências, e assim por diante. Nesse caso, então, não se mostram relevantes nem o processo de socialização, nem a formação das preferências, uma vez que o problema é exclusivamente circunscrito ao processo da tomada de decisão num contexto em que as preferências já estão estruturadas e que são restringidas por certo tipo de arranjo institucional.

Isso significa que tanto a Sociologia como a Ciência Política neo-institucionais tomam as escolhas como unidade de análise, com a diferença de que, enquanto para a primeira as variáveis explicativas seriam exógenas à própria decisão, para a segunda, tais variáveis seriam endógenas ao processo decisório. Mas, em ambos os casos, o mecanismo articulado estabelece que, em um primeiro momento, as instituições agiriam exteriormente, constrangendo/restringindo os indivíduos. Esse processo, ao longo do tempo, geraria uma interiorização/ conhecimento das instituições como cursos possíveis de ação, moldando/estruturando, em um segundo momento, as preferências. Assim, primeiramente, as instituições constrangeriam/restringiriam, ou seja, limitariam as preferências, depois, as instituições as moldariam/estruturariam. Nesse caso é que se poderia falar que determinada instituição está, de fato, institucionalizada. Com isso, as interações 
políticas estão diretamente associadas ao modelo institucional no qual estas estão inseridas, tendo seus resultados influenciados por esse modelo.

Com tal perspectiva, a partir de meados dos anos de 1970, as instituições voltaram ao centro da análise, eleitas como as variáveis explicativas, por excelência, do comportamento e das decisões políticas. $\mathrm{Na}$ verdade, a própria unidade de análise também foi deslocada, passado do comportamento puro e simples, agora relegado ao segundo plano, para as decisões coletivas. Do ponto de vista da Sociologia, o retorno das instituições significou a subdivisão de suas análises em pelo menos duas escolas; uma centrada nas instituições sociais e, outra, no Estado (cf. Hall and Taylor, 1996; Norgaard, 1996; Kato, 1996).

No caso da Ciência Política, o recorte institucional foi processado por uma redução radical das variáveis explicativas fundamentais, concentrandose quase exclusivamente no desenho constitucional e nas regras que presidem o "jogo político". A cultura, as crenças, os valores, enfim, as instituições sociais e até mesmo a estrutura econômica passaram a ser considerados, todos, elementos exógenos tanto ao fenômeno estritamente político como ao conjunto de variáveis explicativas das decisões coletivas. $\mathrm{Na}$ maioria das vezes, tais instituições sequer são consideradas, num processo - para muitos, problemático - semelhante ao ceteris paribus $\mathrm{da}$ Economia, pelas quais estas simplesmente deixam de ser variáveis para se tornarem constantes não intervenientes no fenômeno.

Seja como for, a idéia básica que serve de núcleo epistemológico e metodológico das análises atuais acerca dos fenômenos políticos é a de que os atores respondem estratégica ou moralmente a um conjunto de regras formais ou informais que são circunscritas às instituições. Estas, moldam, condicionam ou induzem os atores a agirem e a decidirem de determinada maneira e acabam, assim, explicando grande parte do que ocorre na dinâmica da política.

\section{Conclusão}

Meu objetivo neste texto foi fazer uma breve reconstrução histórica do paradigma neo-institucionalista da Ciência Política, com a finalidade de destacar dois pontos. O primeiro é que houve dois fatores que concorreram para a "revolução neoinstitucional": (1) a crise do behaviorismo a partir da segunda metade da década de 1960 e (2) a emergência, a partir dos anos de 1950, da análise econômica dos fenômenos políticos sob a ótica dos paradoxos das decisões coletivas. Sob tal perspectiva, minha intenção foi mostrar, mesmo que sucintamente, que o desenvolvimento do paradigma neoinstitucional se deu como um movimento que surgiu a partir das críticas e da rejeição do paradigma até então dominante, o comportamentalismo, de uma parte, e, de outra, a partir da incorporação, de certo modo, crítica, da abordagem econômica à análise do problema político.

O segundo ponto que intentei destacar foi que, não obstante a oposição ao comportamentalismo e ao antigo institucionalismo, a abordagem neo-institucional tem como característica teórica central a síntese epistemológica e metodológica de parte do comportamentalismo com parte do antigo institucionalismo. A volta das instituições ao centro da análise resolveu o problema teórico apresentado pelo paradoxo do voto em assembléias, mas não significou a rejeição completa das premissas do individualismo metodológico, na medida em que a concepção do "Homem-Político" dos neo-institucionalistas é semelhante à concepção do "HomemEconômico". Isso significa que as premissas do altruísmo e da razão, entendida como faculdade destinada à reflexão ética, foram substituídas pelas premissas do egoísmo e da razão como instrumento de cálculo.

$\mathrm{Na}$ verdade, o retorno das instituições, nos moldes adotados pelos neo-institucionalistas da política, somente pôde fazer sentido no contexto do individualismo metodológico da Economia. Isso porque, com esse enfoque, que concebeu um mundo sem instituições e, por isso mesmo, tenebroso, onde decisões nunca são tomadas e a coletividade jamais chega a alguma vontade majoritária estável ou, então, prevalecendo apenas a vontade de um ditador - , torna-se ainda mais evidente a força e a importância das instituições como variáveis determinantes das decisões minimamente justas e estáveis.

Então, a relevância dos modelos constitucionais como objetos de investigação voltou à cena, mas não mais com aquele casaco puído e empoeirado do teórico que só estuda os textos das constituições e deduz da razão abstrata qual o melhor modelo político para se produzir o "Bem". Vestidos 
com seus "aventais de cientistas" e munidos de todas as "ferramentas" - ou, como já se disse, "as peças e as engrenagens" da ciência - das pesquisas empíricas trazidas pelo comportamentalismo, os neo-institucionalistas, agora, investigam, de maneira positiva e analítica, os efeitos dos desenhos institucionais sobre o comportamento dos atores e sobre os resultados políticos.

\section{Notas}

1 Na verdade, o embate contra o republicanismo veio tanto dos pluralistas como dos liberais. Os maiores representantes disso são Dahl (1956), em favor do pluralismo, e Riker (1982), em favor do liberalismo. Ambos, entretanto, tinham em comum a identificação de republicanismo com populismo.

2 Na verdade, é importante destacar que houve pelo menos dois importantes precursores do comportamentalismo. Um deles foi o fisiologista russo Ivan Petrovich Pavlov (1849-1936), o pioneiro da psicologia comportamental. Suas experiências envolvendo o condicionamento animal levaram-no à proposição de que qualquer comportamento, inclusive o humano, seria o resultado de um processo de condicionamento, viabilizado, por sua vez, pelos mecanismos mentais de associação como um sistema de estímulo/resposta. O outro foi o psicólogo e filósofo alemão Wilhelm Wundt (1832-1920), fundador do famoso e pioneiro Instituto Experimental de Psicologia e formulador da abordagem "elementar", por meio da qual costumava dividir a complexidade dos fatores envolvidos no comportamento em elementos básicos e isolados, como determinados sentimentos e sensações, de forma a ser possível mensurá-los como respostas a determinados estímulos.

3 O relato de Durkheim sobre sua visita à Alemanha e suas impressões acerca dos estudos de Wundt foram publicados em 1887. Embora Durkheim seja, essencialmente, um analista de viés institucional, a despeito de sua filiação ao "naturalismo social", sua ênfase nos métodos empíricos observacionais em oposição à abordagem filosófica possibilitou a abertura necessária às influências do comportamentalismo na Sociologia subseqüente. Para maiores detalhes sobre o debate do autor com a Filosofia, com vistas a formular uma ciência da moral, ver: Weiss (2006).
4 Wilhelm Wundt também teve grande influência sobre Malinowski. Este, depois de obter doutoramento em Filosofia, deslocou-se até a Universidade de Leipzig, onde estudou folk psychology com Wundt, entre 1908 e 1910. Graças a tal influência, Malinowski passou a se interessar por Antropologia, o que o levou aos seus estudos de campo em Mailu e nas Ilhas Tobriandesas, onde, então, desenvolveu as clássicas e inovadoras técnicas de observação participante, bem como sua teoria funcionalista da cultura.

5 Parece-me plausível conjecturar que, ao enfatizar a observação sistemática e a descrição densa dos comportamentos como objetivação de "acordos" simbólicos coletivos que cumpririam determinadas funções sociais, Malinowski (1944) avançava em direção a uma forma de comportamentalismo metodológico. Isso porque ao compreender que a ação humana efetiva conduziria ao comportamento organizado e que tal organização é dada por um conjunto de regras e valores, denominado instituições, o autor sugere que se, de um lado, a unidade de análise legítima do fenômeno cultural seriam as próprias instituições, de outro, seu estudo somente seria possível por intermédio da observação dos comportamentos. Segundo o próprio autor, "O valor do behaviorismo é devido, em primeiro lugar, ao fato de que seus métodos são idênticos, no tocante às limitações e vantagens, aos do trabalho de campo antropológico. [...] O princípio fundamental do investigador de campo, assim como também o do behaviorista, é que as idéias, as emoções e as conações nunca prosseguem a conduzir uma existência crítica, oculta dentro das profundezas inexploráveis da mente, consciente ou inconsciente" (Malinowski, 1970, p. 31).

6 Sobre esse debate metodológico na Economia, ver detalhes em Blaug (1993), Mäki e Knudsen (1993), Blackhouse (1994), Hausman (1998) e Hands (2001).

7 A importância de Charles Merriam também pode ser percebida pela constatação da relevância que alguns de seus orientandos vieram a ter no desenvolvimento posterior da Ciência Política norte-americana, entre eles, destacam-se Leonard White, Harold Gosnell, Quincy Wright, Harold Lasswell, V. O. Key, Gabriel Almond, Avery Leiserson, Herbert Simon e David Truman.

8 Geralmente, considera-se que Merriam $(1921,1925)$ foi autor dos dois trabalhos pioneiros do tipo de abordagem que seria adotada mais vigorosamente apenas duas décadas depois, no âmbito do com- 
portamentalismo. Na verdade, há até quem afirme (Gunnell, 2005) que a década de 1920 foi de tal forma crucial para o posterior desenvolvimento desse paradigma que poderia ser considerada um período "pré-behaviorista".

9 Além das atividades acadêmicas, Merriam também atuou na política de seu país, sendo consultor de dois presidentes, o republicano Herbert Hoover [31 ${ }^{\circ}$, que governou no período 1929-1933 e o democrata Franklin Roosevelt, o $32^{\circ}$ da república norte-americana, que governou entre 1933 e 1945.

10 Segundo consta, também foi decisiva para tal conversão a leitura de duas obras anteriores que abordavam a "natureza humana" na política sob a ótica da irracionalidade guiada pelos sentimentos: Graham Wallas (1908) com Human nature in politics e Walter Lippmann (1922) com Public opinion. Da mesma forma, seu irmão, John Merriam, um importante geólogo, trouxe-lhe várias influências das ciências da natureza (cf. Jensen, 1969).

11 De acordo com Gunnell (2005), há ainda outros dois importantes autores da década de 1920 cujas duas obras lançadas naquele período foram igualmente de fundamental importância, quais sejam, Catlin (1927) e Elliott (1928). Gostaria de acrescentar outras obras de grande relevância nesse mesmo momento, cujo foco se concentrava na discussão da aplicação de métodos quantitativos à análise dos fenômenos políticos: Rice $(1928,1931)$ e Gosnell (1933).

12 Trata-se da American Political Science Association, fundada em 1903 e atualmente a maior entidade profissional da área, tanto em número de filiados, como em importância acadêmica [possui atualmente mais de 15 mil membros de cerca de 80 países]. A APSA é a responsável pela edição da American Political Science Review, uma das revistas mais importantes da Ciência Política mundial. Por meio de sua linha editorial, a APSA matiza a prática do que deve ser uma pesquisa científica e sua forma de comunicação. Com isso, colabora preponderantemente para a definição dos parâmetros cosmológicos [o que é o fenômeno político, quais seus elementos mais relevantes, quais as grandes questões que os envolve etc.] e metodológicos da comunidade dos cientistas políticos.

13 Segundo Somit e Tanenhaus, essa absorção ao campo das ciências comportamentais representou, inclusive, uma orientação de ordem prática. Segundo os autores, "o termo ciência comportamentalista foi cunhado por um grupo que tinha fortes inclinações quantitativas, qual seja, o grupo dos cientistas sociais da Universidade de Chicago. Preocupados em atrair verbas federais para as ciências sociais e receosos que estas fossem confundidas com socialismo, eles conceberam o termo ciência comportamentalista" (1967, p 183).

14 Há vários textos que tratam em detalhes de tal paradoxo, seja em nível didático, seja em nível avançado. Para um melhor entendimento a esse respeito, consulte Brams (1976) e Riker (1982).

15 O espaço aqui não permite que se avance sobre todos os aspectos desta questão, mas é importante salientar que há outro autor de fundamental importância no desenvolvimento dos problemas inerentes às decisões coletivas. Trata-se de McKelvey (1976), que desenvolveu aquela que ficou conhecida como a "teoria do caos", relativa às decisões parlamentares. Este autor demonstrou geometricamente que numa decisão coletiva qualquer resultado é possível, mesmo aquele que discrepe da vontade da maioria, na medida em que as decisões em assembléia podem ser manipuladas por intermédio da simples escolha das alternativas a serem votadas e até pela ordem em que estas são colocadas em votação. Com isso, o autor evidenciou, em termos lógicos, o enorme poder daquele que controla a agenda de votação, bem como a importância das "regras do jogo", pois estas definem como o "jogo" é jogado e até quem tem mais chances de ganhá-lo. Para uma exposição didática desse modelo aplicado aos estudos legislativos, ver Limongi (1994).

16 No caso dos estudos sobre o Congresso norte-americano, os esforços dos pesquisadores na tentativa de encontrar empiricamente as variáveis explicativas para a inexistência da instabilidade prevista logicamente pelo teorema de Arrow (1951) ensejaram o desenvolvimento de três linhas de pesquisa conflitantes, a "distributivista", a "informacional" e a "partidária". Para uma análise sintética destas linhas, ver Limongi (1994). Tais abordagens e até mesmo a forma de construir o problema de investigação influenciaram bastante as pesquisas sobre o Congresso brasileiro a partir de meados dos anos de 1990. Neste caso, os pesquisadores têm se dividido entre duas linhas explicativas, quais sejam, a "distributivista", mais pessimista, e a "partidária", mais otimista. Para uma análise da forma de utilização das "teorias positivas" no estudo do legislativo brasileiro, ver Santos (2006). 
17 No caso da Sociologia, o termo mais apropriado é "constrangimento", na medida em que os desvios às normas sempre são "punidos" por algum tipo de reprimenda moral, quando não sanção penal. No caso da Ciência Política, o termo mais apropriado seria "restrição", na medida em que a escola predominante - o institucionalismo racionalista - pressupõe que as decisões encontram alguma oposição em termos de recursos escassos [porcentagem de eleitores disponíveis, dotação orçamentária etc.] ou institucionais [regras eleitorais, regras do processo legislativo etc.], demandando, em face de tais restrições [exógenas], uma transitividade na estrutura de preferências [endógenas], levando os atores, em decorrência de tais restrições, a decisões estratégicas.

\section{BIBLIOGRAFIA}

ADCOCK, C. (1959), Fundamentals of psychology. Londres, Methuem.

ALMOND, Gabriel. (1966), "Political theory and political science". American Political Science Review, 60 (4): 869-879.

. (1988), "The return to State". American Political Science Review, 82 (3): 853-874.

. (1996), "Political science: the history of discipline", in Robert Goodin e Hans-Dieter Klingemann (eds.), A new handbook of political science, Oxford, Oxford University Press.

ALMOND, Gabriel \& POWELL, G. Bingham. (1966), Comparative politics: a developmental approach. Boston, Little, Brown and Company.

ARROW, Kenneth. (1951), Social choice and individual values. Nova York, John Wiley.

BARNES, Harry. (1948), Historical sociology: its origins and development. Nova York, Philosophical Library.

BARRY, Brian. (1978), Sociologists, economists and democracy. Chicago, Chicago University Press.

BAUM, William. (2005), Understanding behaviorism: behavior, culture, and evolution. Oxford, Blackwell.

BLACK, Duncan. (1958), The theory of committees and elections. Cambridge, Cambridge University Press. . (1948), "On the rationale of group decision making". Journal of Political Economy, 56 (1): 23-34.

BLACKHOUSE, Roger. (1994), New directions in economic methodology. Londres, Routledge.

BLAUG, Mark. (1993), A metodologia da economia. São Paulo, Edusp.
BRAMS, Steven. (1976), Paradoxes in politics. Nova York, Free Press.

BUCHANAN, James \& TULLOCK, Gordon. (1962), The calculus of consent: logical foundations of constitutional democracy. Ann Arbor, University of Michigan Press.

BUTLER, David. (1958), The study of political behavior. Londres, Routledge.

CATLIN, G. E. (1927), The science and method of politics. Nova York, Knopf.

CHARLESWORTH, James. (1962), The limits of behavioralism in political science. Philadelphia, American Academy of Political and Social Science.

CHILCOTE, Ronald. (1996), Theories of comparative politics: the search for a paradigm reconsidered. Berkeley, Westview Press.

DAHL, Robert. (1956), A preface to democratic theory. Chicago, University of Chicago Press. . (1961), "The behavioral approach in political science: epithaf for a monument to a successful protest". American Political Science Review, 55 (4): 763-772. . (1963), Modern political analysis. New Jersey, Englewood Cliffs.

DIMAGGIO, Paul \& POWELL, Walter. (1991), "Introduction", in P. Dimaggio e W. Powell (eds.), The new institutionalism in organizational analysis, Chicago, University of Chicago Press.

DOWNS, Anthony. (1957), An economic theory of democracy. Nova York, Harper and Row Publishers.

DRYZEK, John \& LEONARD, Stephen. (1988), "History and discipline in political science". American Political Science Review, 82 (4): 12451260.

DURKHEIM, Émile. (1887), "La science positive de la morale en Allemagne". Revue Philosophique, XXIV: 33-58, 113-142, 275-284. . (1897), Le suicide. Paris, PUF.

EASTON, David. (1953), The political system. Nova York, The Free Press. . (1965), A framework for political analysis. New Jersey, Englewood Cliffs. . (1969), "The new revolution in political science". American Political Science Review, 63 (3): 10-51-1061.

. (1998), "The future of post-behavioral period in political science", in Kristen Monroe (ed.), Contemporary political theory, Berkeley, University of California Press. 
ECKSTEIN, Harry. (1988), "A culturalist theory of political change". American Political Science Review, 82 (3): 789-804.

EGGERTSSON, Thrainn. (1990), Economic behavior and institutions. Cambridge, Cambridge University Press.

ELLIOTT, William. (1928), The pragmatic revolt in politics: syndicalism, facism, and the constitutional State. Nova York, MacMillan.

EULAU, Heinz. (1963), The behavioral persuasion. Nova York, The Free Press.

EULAU, Heinz; ELDERSVELD, Samuel \& JANOWITZ, Morris (eds.). (1956), Political behavior: a reader in theory and research. Illinois, Glencoe.

FARQUAHARSON, Robin. (1969), Theory of voting. New Haven, Yale University Press.

FARR, James. (1995), "Remembering the revolution: behavioralism in American political science", in John Dryzek, James Farr e Stephen Leonard (eds.), Political science in history: research programs and political traditions. Cambridge, Cambridge University Press.

GOSNELL, Harold. (1933), "Statisticians and political scientists". American Political Science Review, 27 (2): 392-403.

GUNNEL, John. (1988), “American political science, liberalism, and the invention of political theory". American Political Science Review, 82 (1):71-87. . (1993), The descent of political theory: the genealogy of an American vocation. Chicago, University of Chicago Press.

. (2004a), "The real revolution in political science". Political Science and Politics, 37 (1): 47-50.

. (2004b), Imaging the American polity: political science and the discourse of democracy. University Park, Pennsylvania State University Press.

. (2005), "Political science on the Cusp: recovering a discipline's past". American Political Science Review, 99 (4): 597-609.

HALL, Peter \& TAYLOR, Rosemary. (1996), "Political science and the three new institutionalism". Political Studies, 44 (5): 936-957.

HANDS, Wade. (2001), Reflection without rules. Cambridge, Cambridge University Press.

HAUSMAN, Daniel. (1998), "Problems with realism in economics". Economics and Politics, 14: 210-225.

HENNEMAN, Richard. (1966), The nature and scope of psychology. Nova York, Brown Company.
HYNEMAN, Charles. (1959), The study of politics. Illinois, Urbana.

IMMERGUT, Ellen. (1998), "The theoretical core of the new institutionalism". Politics and Society, 26 (1): 5-30.

JEPPERSON, Ronald. (1991), "Institutions, institutional effects, and institutionalism", P. Dimaggio e W. Powell (eds.), The new institutionalism in organizational analysis, Chicago, University of Chicago Press.

JENSEN, Richard. (1969), "History and political scientist", in Seymour Lipset (ed.), Politics and the social sciences, Nova York, Oxford University Press.

KATO, Junko. (1996), "Institutions and rationality in politics: varieties of neo-institutionalists". British Journal of Political Science, 26: 553-582.

KNIGHT, Jack \& SENED, Itai. (1995), Explaining social institutions. Ann Arbor, University of Michigan Press.

KUHN, Thomas. (1962), The structure of scientific revolutions. Chicago, Chicago University Press.

LANE, Jan-Erik \& ERSSON, Svent. (2000), The new institutional politics: performance and outcome. Londres, Routledge.

LASSWELL, Harold. (1963), The future of American politics. Nova York, The Free Press.

LEISERSON, Avery. (1956), "Problems of methodology in political research", in W. Eulau, S. Eldersveld e M. Janowitz (eds.), Political behavior: a reader in theory and research, Illinois, The Free Press.

LIMONGI, Fernando. (1994), "O novo institutionalismo e os estudos legislativos: a literatura norte-americana recente". BIB, 37: 3-38.

McKELVEY, Richard. (1976), "Intransitivities in multidimensional voting models and some implications for agenda control". Journal of Economic Theory, 19 (3): 472-482.

MALINOWSKI, B. (1922), Argonauts of the Western pacific. Londres, George Routledge.

(1944), A scientific theory of culture and others essays. Chapel Hill, University of North Carolina Press.

(1970), Uma teoria científica da cultura. Trad. Rio de Janeiro, Zahar.

MÄKI, Gustafsson \& KNUDSEN, C. (1993), Rationality, institutions and economic methodology. Londres, Routledge.

MARCH, James \& OLSEN, John. (1984), "The new institutionalism: organizational factors in 
political life". The American Political Science Review, 78 (2): 734-749.

MERRIAM, Charles. (1921), "The present State of the study of politics". American Political Science Review, 15 (1): 173-185. . (1925), New aspects of politics. Chicago, University of Chicago Press.

MILLER, Warren. (1998), "Political behavior, old and new", in Robert Goodin e Hans-Dieter Klingemann (eds.), A new handbook of political science, Oxford, Oxford University Press.

NEE, V. (1998), "Sources of the new institutionalism", in Mary Brinton e V. Nee (eds.), The new institutionalism in sociology. Nova York, Sage.

NORDLINGER, Eric; LOWI, Theodore \& FABBRINI, Sergio. (1988), "The return to the State: critiques". American Political Science Review, 82 (3): 875-901.

NORGAARD, Sonne. (1996), "Rediscovering reasonable rationality in institutional analysis". European Journal of Political Research, 29: 31-57.

NORTH, Douglas. (1990), Institutions, institutional change and economic development. Cambridge, Cambridge University Press.

O'DONNELL, John. (1987), The origins of behaviorism: American psychology (1870-1920). Nova York, New York University Press.

OSTROM, Elinor. (1986), "An agenda for the study of institutions". Public Choice, 48 (1): 3-25. (1991), "Rational choice theory and institutional analysis: toward complentarity (review essay)". American Political Science Review, 85 (1): 237-243.

PASQUINO, Gianfranco. (1994), "Comportamentismo”, in N. Boobbio, G. Pasquino e N. Matteucci, Dicionário de politica. Brasília, Editora da $\mathrm{UnB}$.

PETERS, B. (1998), "Political institutions, old and new", in Robert Goodin e Hans-Dieter Kligemann (eds.), A new handbook of political science, Oxford, Oxford University Press.

PIERSON, Paul. (1996), "The new politics of the welfare State". World Politics, 48 (2): 143-179.

RANNEY, Austin. (1962), Essays on the behavioral study of politics. Illinois, Urbana.

REDFORD, Emmette. (1961), "Reflections on a discipline". The American Political Science Review, 55 (4): 755-772.

REMMER, Karen. (1997), “Theoretical decay and theoretical development: the resurgence of institutional analysis". Wold Politics, 50 (1): 3461.

RIBA, Clara. (1996), "The use of mathematics in political science: a survey of European and American journals". European Journal of Political Research, 29: 10-25.

RICE, Stuart. (1928), Quantitative methods in politics. Nova York, Knopf.

. (1931), Methods in social science: a case book. Chicago, Chicago University Press.

RIKER, William. (1958). "The paradox of voting and congressional rules for voting on amendments". American Political Science Review, 52 (2): 349-366.

(1959), "A method of determining the significance of roll calls in voting bodies", in John Wahlke e Heins Eulau (eds.), Legislative behavior, Chicago, Free Press.

. (1961), "Voting and the summation of preferences: an interpretative bibliographic review of selected developments during the last decade". American Political Science Review, 55 (4): 900-911.

. (1963), The theory of political coalitions. New Haven, Yale University Press.

(1965), "Arrow's theorem and some examples of the paradox of voting", in John Claunch (ed.), Mathematical applications in political science. Dallas, Arnold Foundation, vol. 1.

(1980), "Implications from the disequilibrium of majority rule for the study of institutions". American Political Science Review, 74 (2): 432-446.

. (1982), Liberalism against populism: a confrotation between the theory of democracy and the theory of social choice. Prospect Heights, Waveland Press.

. (1998), "The ferment of the 1950's and the development of rational choice theory", in Kristen Monroe (ed.), Contemporary political theory, Berkeley, University of California Press.

SANTOS, Manoel Leonardo. (2006), As teorias positivas sobre o organização do Legislativo e as explicações sobre o Congresso Nacional. Dissertação de mestrado, Programa de Pós-Graduação em Ciência Política, UFPE, Recife.

SARTORI, Giovanni. (1997), Comparative constitutional engineering: an inquiry into structures, incentives, and outcomes. Nova York, New York University Press. 
SCHUMPETER, Joseph. (1942), Capitalism, socialism, and democracy. Nova York, Harper and Brothers.

SEARING, Donald. (1991), "Roles, rules, and rationality in the new institutionalism". American Political Science Review, 85 (4): 1239-1260.

SENED, Itai. (1991), "Contemporary theory of institutions in perspective". Journal of Theoretical Politics, 3 (4): 379-402.

SHEPSLE, Kenneth. (1995), "Studying institutions: some lessons from the rational choice theory", in John Dryzek, James Farr e Stephen Leonard (eds.), Political science in history: research programs and political traditions. Cambridge, Cambridge University Press.

. (1986), "The positive theory of legislative institutions: an enrichment of social choice and spatial models", Public Choice, 50 (6): 135-178.

SIMON, Reich. (2000), "The four faces of institutionalism: public policy and pluralistic perspectives". Governance, 13 (4): 501-522.

SKOCPOL, Theda. (1985), "Bringing the State back in: strategies of analysis in current research", in Peter Evans, Dietrich Rueschemeyer e Theda Skocpol, Bringing the State back in, Cambridge, Cambridge University Press.

SMITH, Rogers. (1988), "Political jurisprudence, the new institutionalism, and the future of public law". The American Political Science Review, 82 (1): 90-101.

SOMIT, Albert \& TANENHAUS, Joseph. (1967), The development of American political science: from burgess to behavioralism. Nova York, Allyn and Bacon.

STEINMO, Sven; THELEN, Kathleen \& LONGSTRETH, Frank. (1997), Structuring politics: historical institutionalism in comparative analysis. Cambridge, Cambridge University Press.

TRUMAN, David. (1951), The governmental process. Nova York, The Free Press. . (1965), "Disillusion and regeneration: the quest for a discipline". American Political Science Review, 59 (4): 865-873.

VOEGELIN, Eric. (1952), The new science of politics: an introductory essay. Chicago, Chicago University Press.

WATSON, John. ([1913] 1997), Behaviorism. Nova York, Transaction.

WEISS, Raquel (2006). Émile Durkheim e a Ciência da Moral. Dissertação de Mestrado, Programa de
Pós-Graduação em Sociologia, Universidade de São Paulo.

WOZNIAK, Robert. (1995), Behaviorism: the early years. Nova York, Routledge.

YOUNG, Roland (ed.). (1958), Approachs to the study of politics. Illinois, Evanston. 


\section{COMPORTAMENTO OU INSTITUIÇÕES? AS BASES HISTÓRICAS DO NEO-INSTITUCIONALISMO DA CIÊNCIA POLÍTICA}

\section{Paulo Sérgio Peres}

Palavras-Chave: Neo-Institucionalismo; Comportamentalismo; História da Ciência Política; Instituições Políticas

Meu objetivo neste texto é fazer uma breve reconstrução histórica do paradigma neo-institucionalista da ciência política, com a finalidade de destacar dois pontos. O primeiro é que houve dois fatores que concorreram para a "revolução neo-institucional", quais sejam, a emergência, a partir dos anos de 1950, da análise econômica dos fenômenos políticos sob a ótica dos paradoxos das decisões coletivas e a crise do behaviorismo a partir da segunda metade da década de 1960 O segundo é que a abordagem neo-institucional tem como característica teórica central a síntese epistemológica e metodológica de parte do comportamentalismo com parte do "antigo" institucionalismo.

\section{BEHAVIOR OR INSTITUTIONS? COMPORTEMENT OU THE HISTORICAL BASIS OF THE INSTITUTIONS? LES BASES NEO-INSTITUTIONALISM IN HISTORIQUES DU THE POLITICAL SCIENCES \\ NÉO-INSTITUTIONNALISME DE LA SCIENCE POLITIQUE}

\section{Paulo Sérgio Peres}

Keywords: Neo-Institutionalism; Behaviorism; History of Political Science; Political Institutions.

The article aims to reconstruct historically the Political Science neo-institutionalism paradigm in order to explore two points. The first one consists in arguing that there were two factors that contributed to the neo-institutional "revolution" in politics, which are: the emergence of the economical analysis of political phenomena under the optics of the paradoxes of collective decisions, from the 1950s, and the crisis in behaviorism in the 1960s. The second one consists in arguing that the neo-institutional approach is a synthesis of part of the behaviorism with part of the "old institutionalism".

\section{Paulo Sérgio Peres}

Mots-clés: Néo-Institucionnalisme; Comportementalisme; Histoire de la Science Politique; Institutions Politiques.

Mon objectif dans ce texte est de présenter une brève reconstruction historique du paradigme néo-institutionnaliste de la Science Politique, de façon à démontrer deux points. Le premier se réfère à l'existence de deux facteurs qui ont concouru à la "révolution néo-institutionnelle", qui sont: l'émergence, à partir des années 1950, de l'analyse économique des phénomènes politiques sous l'optique des paradoxes des décisions collectives et de la crise, à partir de la seconde moitié des années 1960, du comportementalisme. Le second se rapporte à l'abordage néo-institutionnel et a pour caractéristique théorique centrale la synthèse épistémologique et méthodologique d'une partie du comportementalisme avec une partie de "l'ancien" institutionnalisme. 